\title{
Inducción de caulogénesis indirecta en Eucalyptus globulus
}

\author{
Induction of indirect caulogenesis in Eucalyptus globulus
}

\author{
Carmen Gloria Larson¹, Cristian Gómez ${ }^{1 *}$, Manuel Sánchez-Olate, ${ }^{1,}$ Darcy Ríos ${ }^{1,2}$ \\ *Autor de correspondencia: ${ }^{1}$ Universidad de Concepción, Centro de Biotecnología, Laboratorio de Cultivo de Tejidos \\ Vegetales, casilla 160-C, Concepción, Chile, Tel.: 56-41-2207241, crigomez@udec.cl \\ ${ }^{2}$ Universidad de Concepción, Facultad de Ciencias Forestales,. Victoria 631, Concepción. Chile.
}

\begin{abstract}
SUMMARY
Caulogenic induction was studied using mature seeds as initial explants. Four concentrations of BAP $\left(0,3,5\right.$ and 7 mg $\left.\mathrm{L}^{-1}\right)$ in the mediums MS, B5 and SP were evaluated for the callus formation. The callus formed in the previous stage was used for the caulogenesis, evaluating the effect of two concentrations of ANA $\left(0.1\right.$ and $\left.0.5 \mathrm{mg} \mathrm{L}^{-1}\right)$, maintaining constant the BAP (1.0 mg $\mathrm{L}^{-1}$ ) and the nutritious media from which they came. In the callus formation, the best results were obtained with $7 \mathrm{mg} \mathrm{L}^{-1}$ of BAP (73\%) when using the medium B5; differing significantly from MS. For the caulogenesis, the medium SP produced the highest values in formation of shoots $(78 \%)$ differing significantly from the media B5 and MS. BAP-ANA's combination (1.0-0.1 mg L $\left.{ }^{-1}\right)$ was more appropriate for the formation of shoots $(62 \%)$, although without statistically differing from the other combination. In conclusion, the callus formation is directly related with the concentration of BAP and the nutritious media used. Also, the concentration of BAP from which the callus and the combinations of BAP and ANA come, for the caulogenesis, do not influence significantly in the formation of adventitious shoots, contrary to the used nutritious media.
\end{abstract}

Key words: Eucalyptus globulus, caulogenesis, callugenesis, auxins, citokinins.

\section{RESUMEN}

Se estudió la inducción caulogénica utilizando semillas maduras como explantos iniciales. Para la callogénesis se evaluaron cuatro concentraciones de BAP $\left(0,3,5\right.$ y $\left.7 \mathrm{mg} \mathrm{L}^{-1}\right)$ en los medios MS, B5 y SP. Para la caulogénesis se utilizaron los callos formados en la etapa anterior, evaluando el efecto de dos concentraciones de ANA $\left(0,1\right.$ y $\left.0,5 \mathrm{mg} \mathrm{L}^{-1}\right)$, manteniendo constante el BAP $\left(1,0 \mathrm{mg} \mathrm{L}^{-1}\right)$ y el medio nutritivo del cual provenían. En la callogénesis los mejores resultados se obtuvieron con $7 \mathrm{mg} \mathrm{L}^{-1}$ de BAP (73\%) al utilizar el medio B5, difiriendo significativamente de MS. Para la caulogénesis, con el medio SP se obtuvieron los valores más altos de formación de brotes (78\%) difiriendo significativamente de los medios B5 y MS. La combinación de BAP-ANA (1,0-0,1 $\left.\mathrm{mg} \mathrm{L}^{-1}\right)$ resultó más apropiada para la formación de brotes $(62 \%)$, aunque sin diferir estadísticamente de la otra combinación. Se concluye que la callogénesis está directamente relacionada con la concentración de BAP y el medio nutritivo utilizado. Además, la concentración de BAP del cual provienen los callos y las combinaciones de BAP y ANA para la caulogénesis, no influyen significativamente en la formación de brotes adventicios, a diferencia del medio nutritivo utilizado.

Palabras clave: Eucalyptus globulus, caulogénesis, callogénesis, auxinas, citoquininas.

\section{INTRODUCCIÓN}

La bibliografía existente sobre micropropagación de Eucalyptus sp. ha abordado principalmente la búsqueda de combinaciones hormonales y medios nutritivos adecuados para cada etapa de la micropropagación (inducción de brotes, elongación y enraizamiento) y para cada especie en particular. Los primeros reportes de micropropagación de Eucalyptus sp. corresponden a Fossar et al. (1974) en Australia, y a Franclet y Boulay (1982) en Francia. Los trabajos se iniciaron en la empresa AFOCEL de Francia en 1973 con la producción masiva de clones de Eucalyptus sp. resistentes al frío. Wiecheteck et al. (1989) encontraron que la combinación óptima para la proliferación de brotes de Eucalyptus viminalis Labill. fue de $0,2 \mathrm{mg} \mathrm{L}^{-1}$ de BAP y $0,1 \mathrm{mg} \mathrm{L}^{-1}$ de $\mathrm{ANA}^{1}$. Para la elongación de brotes, la aplicación de $1,5 \mathrm{gL}^{-1} \mathrm{de}$ carbón activo y $0,1 \mathrm{mg} \mathrm{L}^{-1}$ de $\mathrm{AIB}$, resulta en el tratamiento con mejores resultados, mientras que para la etapa de enraizamiento, la aplicación de $1,0 \mathrm{mg} \mathrm{L}^{-1}$ de AIB y la reducción de la concentración mineral del medio MS a la mitad, produce el mayor porcentaje de enraizamiento ${ }^{1}$.

\footnotetext{
Abreviaciones: ANA: ácido naftalenacético; BAP: 6-bencilaminopurina; B5: Gamborg, solución mineral (Gamborg et al. 1968); MS: Murashige y Skoog, solución mineral (Murashige y Skoog 1962); SP: Barrueto, solución mineral (Barrueto et al. 1999).
} 
Por otra parte, Das y Mitra (1990), en la micropropagación de Eucalyptus tereticornis Sm., establecen que la mejor combinación hormonal para la inducción de brotes adventicios es $1,0 \mathrm{mg} \mathrm{L}^{-1}$ de BAP y $0,1 \mathrm{mg} \mathrm{L}^{-1}$ de ANA en un medio MS. Para la elongación de los brotes es beneficioso disminuir las concentraciones hormonales anteriores, o suplementar el medio de cultivo con carbón activo y giberelina. Para inducir el enraizamiento, es necesario mantener los brotes en $1,0 \mathrm{mg} \mathrm{L}^{-1}$ de AIB en un medio Knop. Además, estos autores puntualizan que el factor clave para la inducción rizogénica es mantener los explantos por un período corto en oscuridad. Este último aspecto también es recalcado por Jambhale y Patil (1996), aunque ellos obtuvieron mejores resultados con una dosis de $4 \mathrm{mg} \mathrm{L}^{-1}$ de AIB por 72 horas, pero manifiestan un marcado efecto clonal, tanto para la proliferación de brotes adventicios como para la inducción rizogénica.

Para el caso específico del enraizamiento, pero en Eucalyptus regnans F. Muell., Blomstead et al. (1991) indican que es más apropiado un periodo de 7 días en 20 mg L ${ }^{-1}$ de AIB en un medio Hogland o Woody Plant Medium, que en MS. También puntualizan que es mejor cambiar los explantos después del pulso hormonal, al medio de cultivo suplementado con carbón activo disminuyendo la intensidad lumínica.

Videla y Chung (1996), en un estudio de micropropagación de Eucalyptus globulus Labill. a través de segmentos nodales, determinan el efecto directo del BAP sobre la proliferación y posterior elongación de los brotes inducidos, encontrando que una concentración de $1,0 \mathrm{mg} \mathrm{L}^{-1}$ de BAP con $0,01 \mathrm{mg} \mathrm{L}^{-1}$ de ANA es más apropiada para la inducción caulogénica. Mientras que la elongación y multiplicación masiva se puede realizar disminuyendo la concentración de BAP hasta $0,1 \mathrm{mg} \mathrm{L}^{-1}$ manteniendo constante la concentración de ANA.

La elongación apropiada de los brotes inducidos sin problemas de deformación foliar es clave para seguir proliferando material seleccionado, ya que un mayor número de entrenudos permite obtener una mayor cantidad de brotes en las etapas de proliferación. Por otra parte, una elongación de buena calidad aporta brotes con características de diámetro y longitud adecuadas para el enraizamiento. Esto es demostrado por Calderón-Baltierra (1994), al indicar que un tratamiento hormonal con $0,1 \mathrm{mg} \mathrm{L}^{-1}$ de $\mathrm{GA}_{3}$ y $440 \mathrm{mg} \mathrm{L}^{-1}$ de calcio (normal en MS), seguido por un tratamiento de oscuridad, es el más adecuado para obtener brotes vigorosos para el enraizamiento. Sin embargo en Eucalyptus gunni Hook., Cortezzi y Méndez (1989) logran elongar 2-2,5 cm con 0,1 y $0,5 \mathrm{mg} \mathrm{L}^{-1}$ de $\mathrm{GA}_{3}$ en presencia de BAP y AIB antes de enraizar. No obstante, no todos los vástagos elongados logran enraizar, posiblemente por efecto directo del genotipo del material.

Estudios más recientes de micropropagación en $E u$ calyptus sp. abordan la posibilidad de obtener mayores tasas de inducción de brotes a través de la vía indirecta, es decir, a través de la formación de callo, en primera instancia, y posteriormente inducción de brotes y elongación de ellos. Al respecto se ha estudiado el efecto del tipo de explanto sobre la producción de brotes (Bandyopadhyay et al. 1999, Barrueto et al. 1999, Hervé et al. 2001).

También se estudia la proliferación masiva a través de técnicas que combinan las condiciones normales de cultivo in vitro con aplicación de $\mathrm{CO}_{2}$ en recipientes cerrados (Zobayed et al. 2000) y finalmente el uso de técnicas como inmersión temporal, en la cual los explantos son sumergidos en medios líquidos con los requerimientos nutricionales y hormonales necesarios para cada etapa de la micropropagación, además de la aplicación de aire fresco para evitar la hiperhidratación de los brotes (Castro y González 2002). Esta técnica, conocida como RITA (Aitken-Christie et al. 1995), ha permitido aumentar considerablemente las tasas de micropropagación en varias especies.

El presente estudio tiene como objetivo estudiar la factibilidad de inducir brotes adventicios a través de una vía indirecta como técnica de propagación de genotipos selectos de Eucalyptus globulus Labill. Se determinará el efecto que tienen diferentes medios nutritivos y distintas concentraciones de reguladores del crecimiento sobre el proceso de callogénesis y caulogénesis, obteniendo, de esta manera, una apropiada línea de inducción de brotes adventicios.

\section{MÉTODOS}

Material vegetal. Como explanto inicial se utilizaron semillas maduras de E. globulus, procedentes del sector Inzunza, Valle Colcura, cuya viabilidad y germinación fueron de $97 \%$ y 96\%, respectivamente (Certificado Centro de Semillas Forestales, Corporación Nacional Forestal, Chillán).

Callogénesis. Las semillas se remojaron durante 24 horas y posteriormente se les aplicó una asepsia superficial. Ésta consistió en un lavado en alcohol al $70 \%$ (v/v) por tres minutos; lavado en agua destilada estéril por un minuto; hipoclorito de sodio comercial al $50 \%$ (v/v) por 15 minutos y finalmente tres lavados con agua destilada estéril de 1, 2 y 3 minutos de duración. Para la inducción de callo se utilizaron los medios nutritivos MS (Murashige y Skoog 1962), SP (Barrueto et al. 1999) y B5 (Gamborg et al. 1968), suplementados con sacarosa $\left(20 \mathrm{~g} \mathrm{~L}^{-1}\right)$ y 6-bencil aminopurina (BAP), en las concentraciones especificadas en el cuadro 1.

Cada tratamiento se suplementó con $40 \mathrm{mg} \mathrm{L}^{-1}$ de PVP, el pH fue ajustado en 5,8 y se adicionó $2,5 \mathrm{gL}^{-1} \mathrm{de}$ Phytagel ${ }^{\circledR}$ (Sigma). La esterilización de los medios se realizó en autoclave, a 1 atm de presión y a $120^{\circ} \mathrm{C}$, durante 20 minutos. Finalmente, las semillas completas, sin cubierta seminal, fueron establecidas en placas de Petri 
Cuadro 1. Tratamientos de inducción de callo desde semillas maduras de Eucalyptus globulus.

Treatments of callus induction from mature seeds of Eucalyptus globulus.

\begin{tabular}{ccc}
\hline Tratamiento & Medio Nutritivo & $\begin{array}{c}\text { Concentración de } \\
\text { BAP }\left(\mathrm{mgL}^{-1}\right)\end{array}$ \\
\hline 1 & MS & 3 \\
2 & MS & 5 \\
3 & MS & 7 \\
4 & B5 & 3 \\
5 & B5 & 5 \\
6 & B5 & 7 \\
7 & SP & 3 \\
8 & SP & 5 \\
9 & SP & 7 \\
$10($ Control 1) & MS & 0 \\
11 (Control 2) & B5 & 0 \\
12 (Control 3) & SP & 0 \\
\hline
\end{tabular}

con $25 \mathrm{ml}$ de cada tratamiento inductor. Se sellaron con parafilm y se mantuvieron durante 75 días en condiciones de oscuridad continua a $23 \pm 2{ }^{\circ} \mathrm{C}$.

Caulogénesis. Para esta etapa se utilizaron como material inicial los callos formados en la etapa anterior, los cuales se depositaron en frascos de cultivo, analizando el efecto combinado de BAP y ANA de acuerdo a los tratamientos descritos en el cuadro 2. Cada tratamiento se suplementó con $40 \mathrm{mg} \mathrm{L}^{-1}$ de PVP, el $\mathrm{pH}$ fue ajustado en 5,8 y se adicionó 2,5 $\mathrm{gL}^{-1}$ de Phytagel $\AA$ (Sigma). La esterilización de los medios se realizó en autoclave, a 1 atm de presión y a $120^{\circ} \mathrm{C}$, durante 20 minutos. Los ensayos de caulogénesis se mantuvieron durante 45 días bajo fotoperíodo de 16 horas luz y 8 horas de oscuridad, a una intensidad lumínica constante de 3.000 Lux y a una temperatura de $25 \pm 1^{\circ} \mathrm{C}$.

Tipos de análisis. En la etapa de callogénesis, fue evaluado el porcentaje de callos por tratamiento, mientras que, en la etapa de caulogénesis, se evaluó el porcentaje de callos que presentaron formación de brotes adventicios.

Diseño experimental. Para la etapa de callogénesis se utilizó un diseño completamente aleatorio con un experimento factorial 3 x 4 (Montgomery 1991). Los factores a analizar fueron medio de cultivo (tres niveles) y concentración de BAP (cuatro niveles). Para esta etapa se ensayaron 12 tratamientos, cada uno con cinco repeticiones y diez explantos (semillas) por repetición. La unidad muestral estuvo conformada por una placa de Petri con diez semillas. Al analizar el número de callos formados por tratamiento se utilizó el test no paramétri-
Cuadro 2. Tratamientos de inducción de brotes, desde callos formados en la etapa de callogénesis.

Treatments of shoots induction from callus formed in callugenesis.

\begin{tabular}{cccc}
\hline Tratamiento & $\begin{array}{c}\text { Medio } \\
\text { Nutritivo }\end{array}$ & $\begin{array}{c}\text { Concentración } \\
\text { de BAP (mgL } \\
\text { original }\end{array}$ & $\begin{array}{c}\text { Concentración de } \\
\text { BAP-ANA } \\
\left(\mathrm{mgL}^{-1}\right)\end{array}$ \\
\hline 1 & MS & BAP 3 & $1-0,1$ \\
2 & MS & BAP 3 & $1-0,5$ \\
3 & MS & BAP 5 & $1-0,1$ \\
4 & MS & BAP 5 & $1-0,5$ \\
5 & MS & BAP 7 & $1-0,1$ \\
6 & MS & BAP 7 & $1-0,5$ \\
7 & B5 & BAP 3 & $1-0,1$ \\
8 & B5 & BAP 3 & $1-0,5$ \\
9 & B5 & BAP 5 & $1-0,1$ \\
10 & B5 & BAP 5 & $1-0,5$ \\
11 & B5 & BAP 7 & $1-0,1$ \\
12 & B5 & BAP 7 & $1-0,5$ \\
13 & SP & BAP 3 & $1-0,1$ \\
14 & SP & BAP 3 & $1-0,5$ \\
15 & SP & BAP 5 & $1-0,1$ \\
16 & SP & BAP 5 & $1-0,5$ \\
17 & SP & BAP 7 & $1-0,1$ \\
18 & SP & BAP 7 & $1-0,5$ \\
\hline
\end{tabular}

co Kruskal Wallis, con un nivel de significancia de 0,05 $(\alpha)$, ya que las variables no cumplían con la condición de normalidad. Al existir diferencias significativas entre los tratamientos se aplicó el test de Dunn (Montgomery 1991). Para la etapa de inducción de brotes también se utilizó un diseño completamente aleatorio, con un experimento factorial. Los factores fueron medio de cultivo (tres niveles), concentración de origen (tres niveles) y combinación BAP-ANA (dos niveles), quedando un experimento $3 \times 3 \times 2$. Cada tratamiento tuvo cinco repeticiones, con tres explantos por repetición. La unidad muestral estuvo conformada por cada frasco. Al igual que en la etapa anterior, se utilizó el test Kruskal Wallis con un nivel de significancia de 0,05 ( $\alpha$ ). Las diferencias significativas entre los tratamientos se determinaron mediante el test de Dunn (Montgomery 1991).

\section{RESULTADOS}

Callogénesis. El porcentaje de callogénesis por tratamiento fue máximo en el tratamiento $6(72 \%)$ y mínimo en los tratamientos 10, 11 y 12 (Controles), donde no hubo formación de callos y las respuestas observadas fueron germinación de las semillas. Por otro lado, los tratamientos 5 y 9 presentaron un valor de $64 \%$ y $65 \%$, 
respectivamente, siendo éstos y el tratamiento 6 los mejores. Los demás tratamientos presentaron porcentajes más bajos, difiriendo significativamente con los que entregaron valores altos (figura 1A).

En relación al efecto del medio nutritivo, la menor callogénesis se obtuvo en el medio MS, con un valor cercano al 19\%; en cambio, en los medios SP y B5, se alcanzaron valores de $40 \%$ y $44 \%$, respectivamente, existiendo diferencias significativas entre MS y los otros dos medios nutritivos ensayados (figura 1B).

Analizando la formación de callos con respecto a la concentración de BAP, hubo diferencias significativas en todas las concentraciones estudiadas, fluctuando entre un $0 \%$ en el tratamiento control $\left(0 \mathrm{mg} \mathrm{L}^{-1} \mathrm{BAP}\right)$, hasta un $60 \%$ en la concentración $7 \mathrm{mg} \mathrm{L}^{-1}$ de BAP (figura 1C).

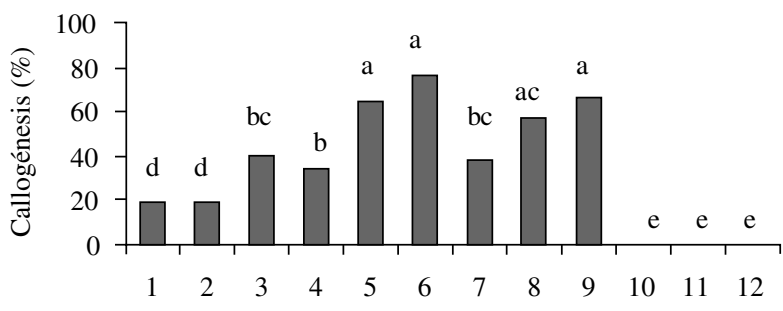

A

Tratamientos

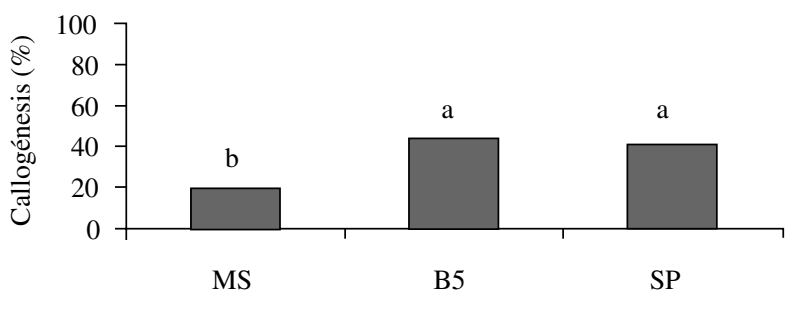

B

Medio Nutritivo

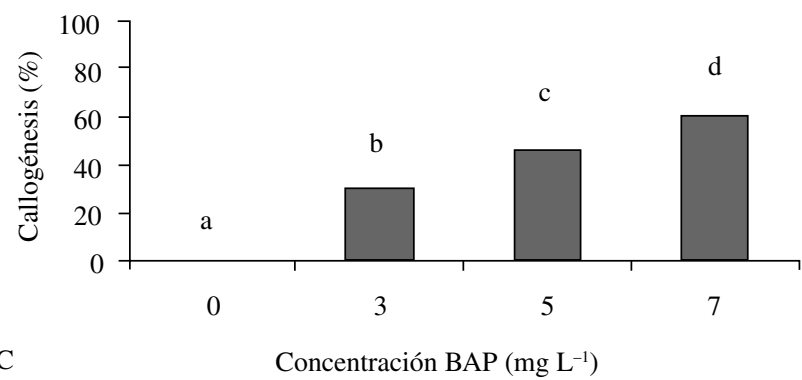

Figura 1. Aspectos cuantitativos de la callogénesis. A) Porcentaje de callogénesis por tratamiento de inducción. B) Porcentaje de callogénesis en función del medio nutritivo.

C) Porcentaje de callogénesis en función de la concentración de BAP. Letras distintas sobre las barras indican diferencias significativas $(*=P<0,05)$.

Quantitative aspects of the callus formation. A) Percentage in function of induction treatment. B) Percentage in function of nutritious media. C) Percentage in function of the concentration of BAP. Different letters on the bars indicate significant differences $(*=P<0.05)$.
Con respecto a los aspectos macromorfológicos observados en los callos, estos no difieren entre tratamientos. Se observó que el callo principalmente se forma desde los cotiledones y, en segundo lugar, desde el meristema radicular. Inicialmente el callo tiene un aspecto friable y de color blanco. Al final del período de inducción callogénica, su aspecto es compacto, presentando zonas con oxidación fenólica, que le dan un tono café oscuro (figura 3A).

Caulogénesis. Los callos que presentaron formación de brotes alcanzaron valores muy variados dentro de los tratamientos, encontrándose diferencias significativas entre ellos. Los porcentajes más altos de caulogénesis se obtuvieron en los tratamientos 13 y 14 con un $100 \%$ de formación de brotes en todos los explantos. Los valores más bajos se cuantificaron en los tratamientos 1 y 6 , donde la caulogénesis alcanzó solo a un 20\% (figura 2A).

De los callos con respuesta caulogénica, con respecto al medio nutritivo utilizado, se observó que el medio SP alcanzó el mayor valor de formación de brotes, con un $78 \%$, a diferencia de los medios MS y B5, los cuales alcanzaron un $47 \%$ y $53 \%$, respectivamente. El valor registrado para SP difiere significativamente con respecto a los valores de MS y B5 (figura 2B).

Al analizar el porcentaje de callos con formación de brotes con respecto al origen de los explantos, aquellos que provenían de la concentración BAP $7 \mathrm{mg} \mathrm{L}^{-1}$ presentaron la menor formación de brotes, con un $46 \%$. A diferencia de éstos, el mayor porcentaje se obtuvo en los explantos que provenían de la concentración $5 \mathrm{mg} \mathrm{L}^{-1}$, con un $68 \%$. A su vez, la concentración $3 \mathrm{mg} \mathrm{L}^{-1}$ alcanzó un valor de 64\%. Sin embargo, no existen diferencias significativas entre las concentraciones iniciales de BAP utilizadas en la etapa de callogénesis (figura 2C).

Del porcentaje de callos con formación de brotes, con respecto a la concentración utilizada de BAP y ANA, la combinación 1-0,1 $\mathrm{mg} \mathrm{L}^{-1}$ (BAP-ANA) obtuvo un mayor porcentaje de callos con formación de brotes $(62 \%)$, a diferencia de la concentración 1-0,5 mg L ${ }^{-1}$ (BAPANA), que alcanzó un valor de 57\%. Sin embargo, las diferencias señaladas no son estadísticamente significativas (figura 2D).

Con respecto a los aspectos macromorfológicos observados en los callos que presentaron formación de brotes, su aspecto visual fue diverso, ya que hubo callos con zonas blancas, verdes, cafés y rojas. Aquellas zonas de los callos que originalmente eran blancas, después del período de callogénesis adquirieron coloración verde en condiciones de fotoperíodo, formando pequeños brotes a los 20 días de tratamiento. Estos alcanzaron una longitud promedio de $1 \mathrm{~cm}$ al término del período de inducción caulogénica (figura 3B, 3C y 3D). Se observó además que, durante el transcurso del período de inducción caulogénica, los callos que dieron origen a brotes fueron aumentando su grado de oxidación. Sin embargo, no se observó hiperhidricidad en los brotes ni en las hojas inducidas. 


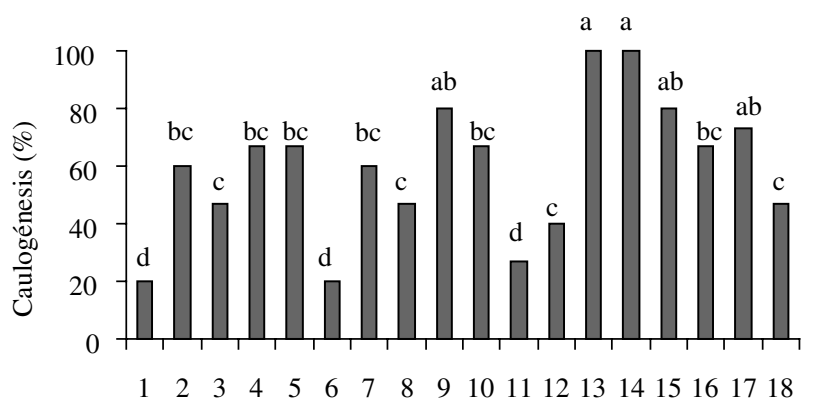

A

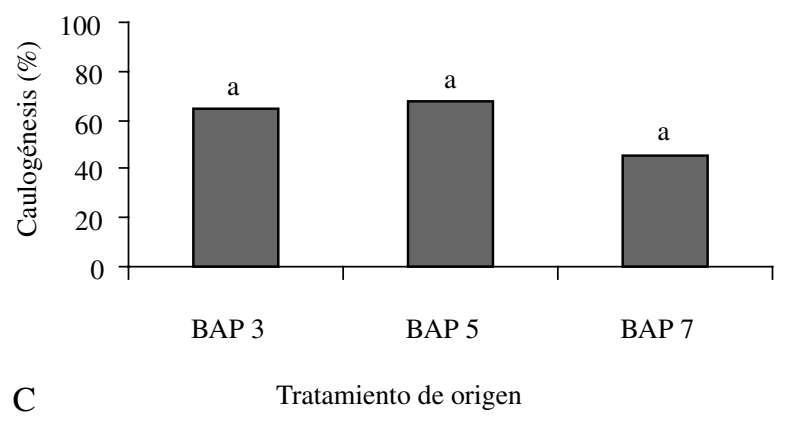

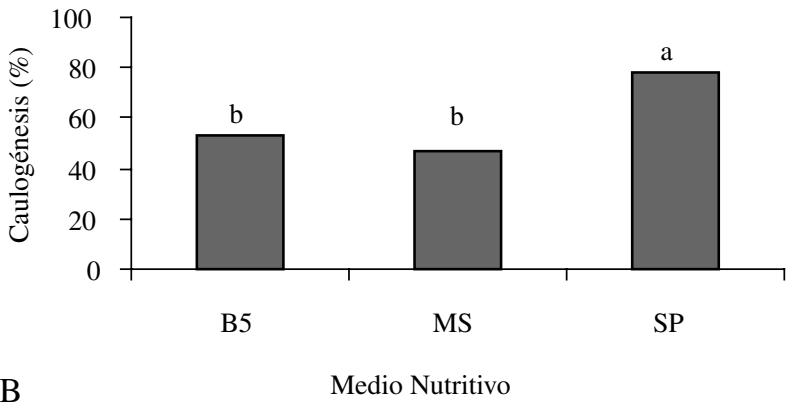

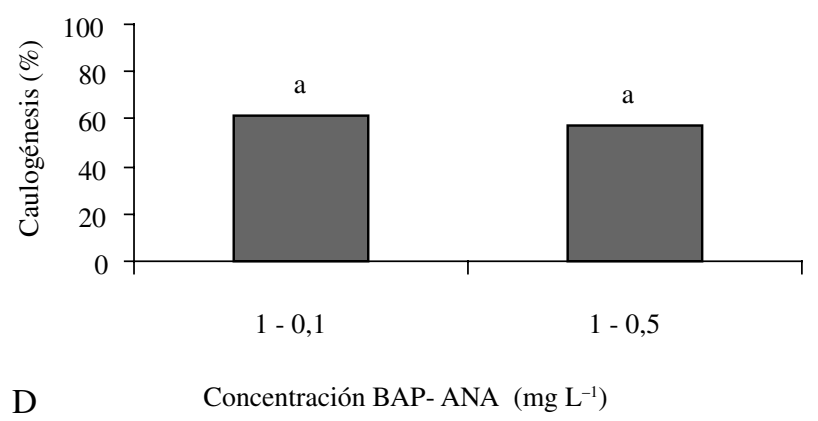

Figura 2. Aspectos cuantitativos de la caulogénesis adventicia. A) Porcentaje de caulogénesis en los diferentes tratamientos B) Porcentaje de caulogénesis en función del medio nutritivo. C) Porcentaje de caulogénesis en función de la concentración de BAP original. D) Porcentaje de caulogénesis en función de la combinación de BAP-ANA (mg L ${ }^{-1}$ ) utilizada. Letras distintas sobre las barras indican diferencias significativas $(*=P<0,05)$.

Quantitative aspects of the adventitious caulogenesis. A) Caulogenesis percentage in the different treatments. B) Caulogenesis percentage in function of the nutritious media. C) Caulogenesis percentage in function of the concentration of original BAP. D) Caulogenesis percentage in function of the combination of BAP-ANA $\left(\mathrm{mg} \mathrm{L}^{-1}\right)$ used. Different letters on the bars indicate significant differences (* $=P<0.05)$.

\section{DISCUSIÓN}

Al utilizar BAP como citoquinina inductora de callogénesis, se obtuvieron resultados positivos, aunque en valores menores que los resultados obtenidos por Barrueto et al. (1999), quienes alcanzaron formación de callos cercanos al $100 \%$, utilizando como hormona de inducción Tidiazuron (TDZ), en semillas del híbrido E. grandis x E. urophylla. La rapidez en la formación de los callos y el tamaño al final del periodo de inducción está directamente relacionado con las concentraciones de BAP aplicadas. De la misma manera, Barrueto et al. (1999) concluyen que el incremento de las concentraciones de TDZ influye directamente en la formación de callos.

Para la etapa de caulogénesis, las diferencias significativas obtenidas con respecto al medio nutritivo utilizado se explican por la concentración de amonio presente en cada uno de ellos. Al respecto, Pierik (1990) indica que la disminución de la concentración de amonio en la solución mineral es importante para estimular la formación de brotes adventicios desde una masa callosa. En este estudio, el medio nutritivo SP es una modificación de MS, ya que las concentraciones de macro y micronu- trientes están diluidas a la mitad. Por lo tanto, la concentración de amonio en SP es de 10,3 mM, siendo más adecuada para esta especie que las concentraciones de MS (20,6 mM) y B5 (2 mM).

Los resultados presentados en la figura $2 \mathrm{C}$ indican que no existen diferencias significativas entre los tratamientos de origen. Es importante considerar este aspecto, ya que tiempos prolongados de exposición a BAP pueden producir un agotamiento fisiológico del material (Trindade et al. 1990), lo que obligaría a mantener los explantos en un medio base sin hormonas para liberarlos de estas concentraciones, facilitando posteriormente su respuesta caulogénica. Este agotamiento fisiológico se explica por un bloqueo de los receptores de membrana a las altas concentraciones de reguladores de crecimiento aplicados (Gómez 2004). Otra respuesta posible la dan Muhitch y Fletcher (1985), quienes establecen que, al envejecer las células en cultivo, aumenta la probabilidad de sintetizar productos nocivos para el crecimiento vegetal, por lo cual la tasa de proliferación decae a medida que el número de subcultivos aumenta.

Para la etapa de caulogénesis, Pierik (1990) y Barrueto et al. (1999) indican que la formación de brotes es 


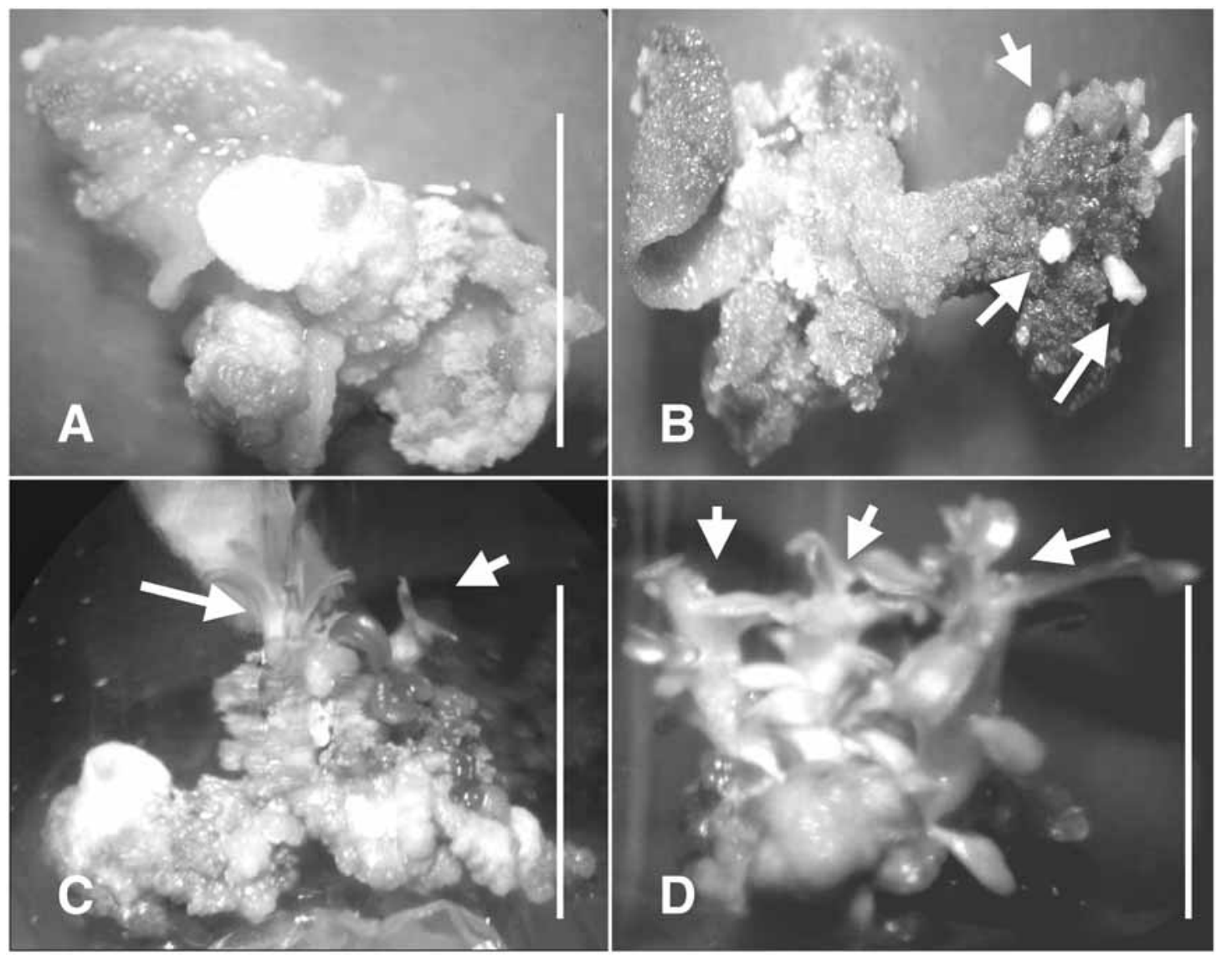

Figura 3. Aspectos macromorfológicos de la inducción callogénica y caulogénica. A) Callo formado después del periodo de inducción. B) Inicio de la formación de brotes después de 20 días en tratamientos de caulogénesis. C) Caulogénesis adventicia a los 35 días D) Caulogénesis al final del periodo de formación de brotes. Flechas indican formación de brotes. Barras $=1,0 \mathrm{~cm}$.

Macromorphologic aspects of the callus induction and caulogenic induction. A) Callus formed after the period of induction. B) Beginning of buds formation after 20 days in caulogenesis treatments. C) Adventitious caulogenesis to the 35 days. D) Caulogenesis at the end of the period of buds formation. Arrows indicate formation of buds. Bar $=1.0 \mathrm{~cm}$.

positiva al utilizar concentraciones mayores de citoquininas que auxinas. Esto se corrobora en la combinación 1$0,1 \mathrm{mg} \mathrm{L}^{-1}$ (BAP-ANA) al alcanzar valores más altos de caulogénesis. Según Durand-Cresswell et al. (1982) y Ahuja (1993), el desencadenamiento de la caulogénesis in vitro resulta de la interacción entre las citoquininas y auxinas, pero esto siempre depende de la especie, el tipo de explanto y su edad fisiológica. Dicho proceso exige una relación citoquinina/auxina elevada; de esta manera, el aumento en la concentración de auxina puede necesitar igualmente el aumento de concentración en citoquinina, por lo cual la caulogénesis dependería de una relación óptima entre las concentraciones totales de citoquininas y de auxinas exógenas y endógenas (Margara 1988, Pierik 1990).

Según Trindade et al. (1990) la aplicación de citoquinina es importante para la cantidad y calidad de los brotes de E. globulus inducidos in vitro. Sin esta aplicación, es posible obtener hasta un $75 \%$ de necrosis en los brotes inducidos después de un cierto número de subcultivos. Estos mismos autores indican que la aplicación de BAP en los mismos rangos de concentración que kinetina produce promedios más altos de formación de brotes. Además, con BAP es posible obtener brotes más vigorosos (figura 3D), mientras que kinetina induce hojas deformes y pequeñas.

A pesar de que existe información importante sobre micropropagación en varias especies de Eucalyptus, son pocos los reportes que profundizan en las causas fisiológicas, identificando el rol de cada uno de los reguladores del crecimiento aplicados a los medios de cultivo (Trindade et al. 1990, Bennett et al. 1994, Calderón-Baltierra 1994). Además, los procesos de control involucrados en la multiplicación no están del todo claros, ya que la mayoría de los estudios da prioridad a la optimización de los protocolos propiamente tal.

La formación de brotes adventicios desde una masa callosa se explica por la capacidad de algunas células de responder a los reguladores de crecimiento aplicados y expresar nuevas vías de desarrollo a través de la diferenciación de centros meristemáticos. Azmi et al. (1997), en la organogénesis directa de E. globulus, describen el 
origen de los brotes a partir de un grupo meristemático de forma tetraédrica ubicado en las proximidades de glándulas de aceite. Esta zona, altamente competente, se diferencia directamente en brotes al ser estimulada principalmente con BA, como también ha sido descrito por Trindade y Pais (1990). De igual manera, en la organogénesis de E. gunni, Hervé et al. (2001) describen el origen de brotes adventicios a partir de ciertas células con alto contenido de clorofila, ubicadas en capas subepidérmicas, al utilizar nudos y entrenudos, mientras que al utilizar hojas la neoformación implica participación del sistema vascular. A diferencia de lo que sucede en la formación de embriones somáticos (Muralidharan et al. 1989, Termignoni et al. 1996), el desarrollo de estos brotes adventicios implica una fuerte unión con el tejido materno a través del sistema vascular (Hervé et al. 2001). Para Hartman y Kester (1987) la formación de brotes adventicios puede conducir a tasas muy elevadas de multiplicación, más altas que las que se obtienen de ramas axilares. Si esta formación de brotes es a través de caulogénesis indirecta, se puede producir un mayor número de plantas por unidad de tiempo, en comparación con la organogénesis directa desde cualquier tejido vegetal, lo que implica una gran ventaja al momento de realizar la propagación vegetativa de una especie de interés económico (Aitken-Christie et al. 1995).

\section{CONCLUSIONES}

- En la etapa de callogénesis, la concentración de BAP y el medio nutritivo utilizado influyen significativamente en la formación de callos desde semillas maduras.

- El medio SP presenta mayores porcentajes para la inducción caulogénica, difiriendo significativamente de los medios MS y B5.

- En la caulogénesis adventicia, las concentraciones originales de BAP y las combinaciones de BAP-ANA no ejercen un efecto significativo sobre la cantidad y calidad de los nuevos brotes.

\section{REFERENCIAS}

Ahuja M. 1993. Biotechnology and clonal forestry. In Ahuja M y W Libby (Eds.). Clonal Forestry I: genetics and biotechnology. Institute of Forest Genetics. Germany. p. 135144.

Aitken-Christie J, T Kosal, S Takayama. 1995. Automation in plant tissue culture. General introduction and overview. p. 1-18. In Aitken-Christie J, T Kozai, MAL Smith (eds.) I Automation and environmental control in plant tissue culture. Kluwer Academic Publishers, Dordrecht, The Netherlands.

Azmi A, M Noin, P Landré, M Prouteau, A Boudet, D Chriqui. 1997. High frequency plant regeneration from Eucalyptus globulus Labill. Hypocotils: Ontogenesis and ploidy level of the regenerants. Plant Cell, Tissue and Organ Culture 51: 9-16.

Bandyopadhyay S, K Cane, G Rasmussen, J Hamill. 1999. Efficient plant regeneration from seedling explants of two commercially important temperate eucalypt species $E u$ calyptus nitens and Eucalyptus globulus. Plant Science 140: 189-198.

Barrueto L, A Machado, S Carvhaleira, A Brasileiro. 1999. Plant regeneration from seedling explant of $E$. grandis $x$ E. urophylla. Plant Cell, Tissue and Organ Culture. 56: 17-23.

Bennett I, J McComb, C Tonkin, D McDavid. 1994. Alternating cytokinins in multiplication media stimulates in vitro shoot growth and rooting of Eucalyptus globulus Labill. Annals of Botany 74: 53-58.

Blomstead C, J Cameron, P Whiteman, S Chandler. 1991. Micropropagation of juvenile Eucalyptus regnans (Mountain Ash). Australian Journal Botany 39: 179-186.

Calderón-Baltierra X. 1994. Influencia del calcio y ácido giberélico en el alargamiento de brotes adventicios in vitro de Eucalyptus globulus. Bosque 15 (1): 33-38.

Castro D, J González. 2002. Micropropagación de Eucalipto (Eucalyptus grandis Hill ex Maiden) en el sistema de inmersión temporal. Agricultura Técnica. 62 (1): 68-78.

Cortezzi M, S Méndez. 1989. Micropropagation of Eucalyptus dunni Maid. Annals of Forest Science 46: 140-144.

Das T, G Mitra. 1990. Micropropagation of Eucalyptus tereticornis. Plant Cell, Tissue and Organ Culture. 22: 95-103.

Durand-Cresswell R, M Boulay, A Franclet. 1982. Vegetative propagation of Eucalyptus. In Bonga J y D Durzan eds. Tissue culture in forestry. Martinus Nijhaff, The Hague p. $150-181$.

Fossard D, C Nitsch, R Cresswell, E Lee. 1974. Tissue and organ culture of Eucalyptus. New Zealand Journal Forest Science. 4: 267-278.

Franclet A., M. Boulay. 1982. Micropropagation of frost resistant Eucalyptus clones. Australian Journal Forest Research. 13: $83-89$.

Gamborg O, R Miller, K Ojimai. 1968. Nutrient requirements of suspension cultures of soybean root cells. Experimental Cell Research. 50(1): 151-158.

Gómez C. 2004. Organogénesis e inducción de embriogénesis somática en Eucalyptus globulus Labill. Tesis Magíster en Ciencias Forestales. Concepción, Chile. Facultad de Ciencias Forestales, Universidad de Concepción. 112 p.

Hartman H, D Kester. 1987. Plant propagation, principles and practices. ed. New Jersey. Prentice Hall. 640 p.

Hervé P, A Jauneaud, M Paques, J Marien, A Boudet, Ch Teulieres. 2001. A procedure for shoot organogenesis in vitro from leaves and nodes of an elite Eucalyptus gunnii clone: comparative histology. Plant Science 161: 645-653.

Jambhale N, S Patil. 1996. Micropropagation of elite Eucalyptus types through shoot tip culture. Indian Forester 1: 61-64.

Margara J. 1988. Multiplicación vegetativa y cultivo in vitro: los meristemas y la organogénesis. Ediciones Mundi-Prensa. Madrid. España. 232 p.

Montgomery D. 1991. Diseño y análisis de experimentos. Grupo editorial Iberoamericana. México. 589 p.

Muhitch M, J Fletcher. 1985. Influence of culture age and spd treatment on the accumulation of phenolic compounds in suspension cultures. Plant Physiology. 78: 25-28. 
Muralidharan E, P Gupta, A Mascarenhas. 1989. Plantlet production through high frequency somatic embryogenesis in long term cultures of Eucalyptus citriodora. Plant Cell Reports. 8: 41-43.

Murashige T, F Skoog. 1962. A revised medium for rapid growth and bioassays with tobacco tissue cultures. Physiol. Plant., 15: 473-497.

Pierik R. 1990. Multiplicación in vitro de las plantas superiores. Ediciones Mundi-Prensa. Madrid. España. 326 p.

Termignoni R, P Wang, P Ch Hu. 1996. Somatic embryo induction in Eucalyptus dunnii. Plant Cell, Tissue and Organ Culture. 45: 129-137.

Trindade H, J Ferreira, M Pais, R Aloni. 1990. The role of citokinin and auxin in rapid multiplication of shoots of Eucalyptus globulus grown in vitro. Australian Forestry 53 (3): 221-223.

Videla P, P Chung. 1996. Micropropagación de Eucalyptus globulus a través de segmentos nodales. Ciencia e Investigación Forestal. 10 (2): 165-173.

Wiecheteck M, M Cortezzi, A De Araujo. 1989. Micropropagation of Eucalyptus viminalis Labill. Annals of Forest Science. 46: 161-164.

Zobayed S, F Afreen-Zobayed, C Kubota, T Kozai. 2000. Mass propagation of Eucalyptus camaldulensis in scaled-up vessel under in vitro photoautotrophic condition. Annals of Botany 85: 587-592.

Recibido: 21.11 .05

Aceptado: 23.10.06 